\title{
Effect of Graphene on Wear Properties of Aluminum and Alumina Matrix Nanocomposites
}

\author{
Solomon Hanson Duntu ${ }^{1}$, Mohammad Islam ${ }^{2}$, Solomon Boakye-Yiadom ${ }^{1}$ \\ 1. Department of Mechanical Engineering, York University, Toronto, Canada. \\ 2. Advanced Manufacturing Institute, King Saud University, Riyahd, Saudi Arabia.
}

Graphene and carbon nanotubes have been utilized as reinforcement phases in nanostructured ceramic and metallic matrix nanocomposites that are adapted for several structural applications. The incorporation of graphene into these matrices has led to the improvement of fracture toughness especially in brittle ceramics, and other mechanical and physical properties when they are homogeneously dispersed within the matrix phase. With the combination of large specific area, high aspect ratio and outstanding mechanical properties, these suitable nano-phases provide toughening effect in the base material matrix typically by crack bridging and pinning, and crack deflection [1]. Reports have also shown that the substantial grain refinement capabilities of graphene and carbon nanotubes within the matrix contribute immensely to the enhanced mechanical properties. The addition of graphene also provides good lubrication and improves wear resistance of metallic and ceramic based composites such as aluminum, alumina and silicon carbide. Recent studies have shown that desirable properties in graphene reinforced composites is dependent on several factors such as phase homogeneity and interfacial bonding, which are mostly dependent on the processing route[2]. Whilst most studies have reported significant improvement in mechanical properties with graphene addition in these matrix materials, other investigations have shown that the properties such as wear resistance and fracture toughness deplete with certain amounts of graphene and CNT inclusions. This is mainly attributed to processing challenges such as carbon agglomeration and retention of graphene nanostructures within the matrix after consolidation. In the current study, attempt has been made to homogeneously disperse graphene within alumina and aluminum matrix to form nanocomposites using a colloidal mixing route followed by high temperature sintering. The final consolidated composites were subjected to reciprocating sliding wear test under constant loads. The effect of graphene inclusion on the microstructure and wear characteristics of the various nanocomposites are discussed below.

Figure 1a shows the coarse-grained microstructure of Pure Al after sintering with apparent surface pores and remnants of $\mathrm{Al}$ powder particles within the structure. Extensive grain refinement with the addition of $0.5 \mathrm{vol} \%$ graphene is depicted in Fig(1d). The fine grain microstructure is evidence of the ability of graphene to restrict abnormal grain growth of the matrix during sintering as reported in literature [2]. Wear tracks in Pure $\mathrm{Al}$ and $\mathrm{Al}+0.5 \mathrm{Gn}$ show large peel-off and delamination areas in sliding direction of both nanocomposites (Fig. $1 \mathrm{~b}$ and 1e). There are also deeper and larger cracks on debris particles of Pure Al than $\mathrm{Al}+0.5 \mathrm{Gn}$ showing crack bridging effect of graphene. In Figure 2, a similar trend is observed in ceramic alumina revealing a relatively refined matrix phase with the addition of $0.5 \mathrm{vol} \%$ graphene (Fig $2 \mathrm{a}$ and 2d). It is also observed that there is relatively larger peeling off within wear track of Pure $\mathrm{Al}_{2} \mathrm{O}_{3}$ but a finer wear with small pull-out is exhibited within $\mathrm{Al}_{2} \mathrm{O}_{3}+0.5 \mathrm{Gn}$. Figures $2 \mathrm{c}$ and $2 \mathrm{f}$ shows the wear debris of revealing that small particles are removed from material during wear testing. This due to the refined microstructure of $\mathrm{Al}_{2} \mathrm{O}_{3}+0.5 \mathrm{Gn}$ with good lubricating effect of graphene to reduce frictional wear. The results from microstructure and wear nature attest to the grain refinement effect and improved wear properties of graphene in the $\mathrm{Al}$ and $\mathrm{Al}_{2} \mathrm{O}_{3}$ matrix phase. 


\section{References:}

[1] MT Markandan, K Chin and JK Tan, J. Mater. Res 32 (2017), p. 84.

[2] I Ahmad, B Yazdani and Y Zhu, Nanomaterials 5(1) (2015), p. 90.

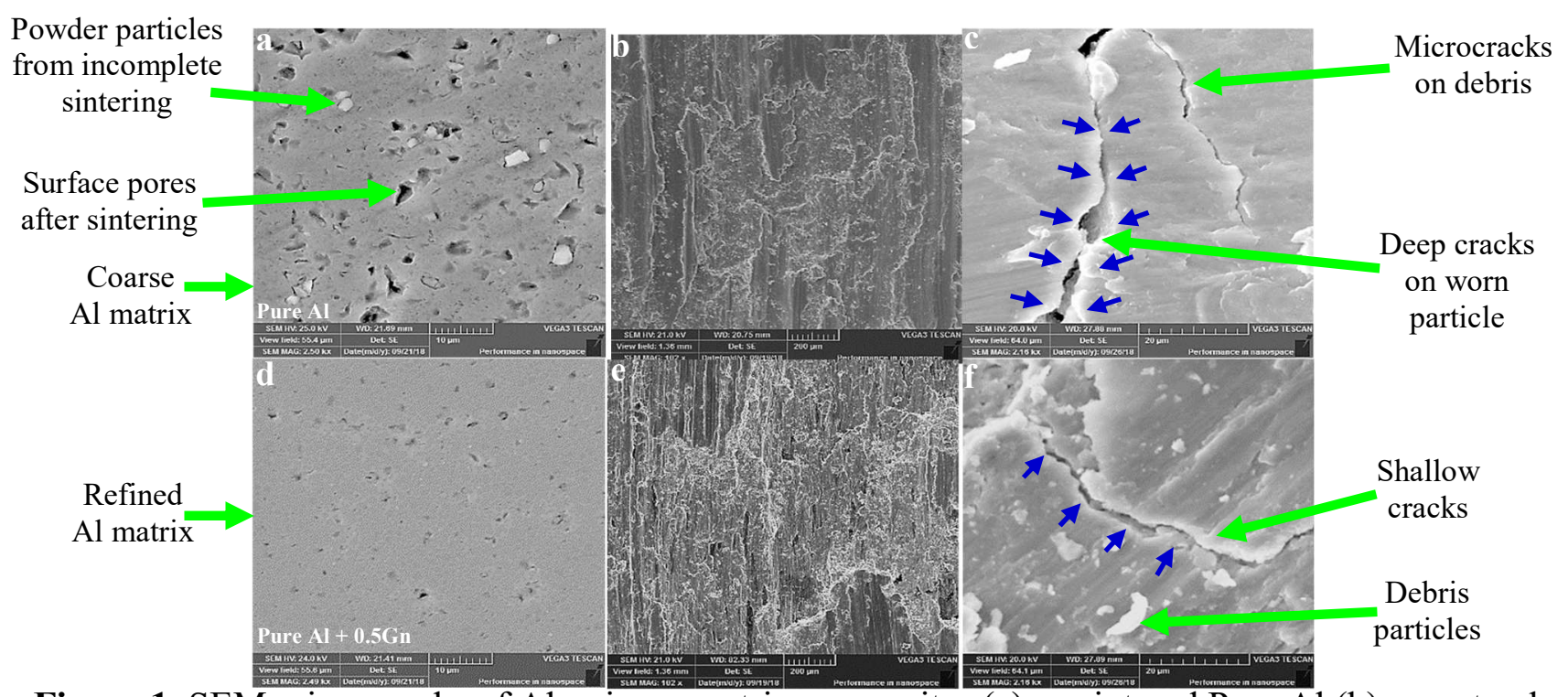

Figure 1. SEM micrographs of Aluminum matrix composites (a) as-sintered Pure Al (b) wear track of Pure Al showing major deep peel-off areas (c) wear debris of pure Al with cracks deeper cracks (d) assintered $\mathrm{Al}+0.5 \mathrm{Gn}$ with refined $\mathrm{Al}$ matrix (e) within wear track of $\mathrm{Al}+0.5 \mathrm{Gn}$ showing small peel-off sites $(\mathrm{g})$ wear debris of $\mathrm{Al}+0.5 \mathrm{Gn}$ composite showing shallow cracks

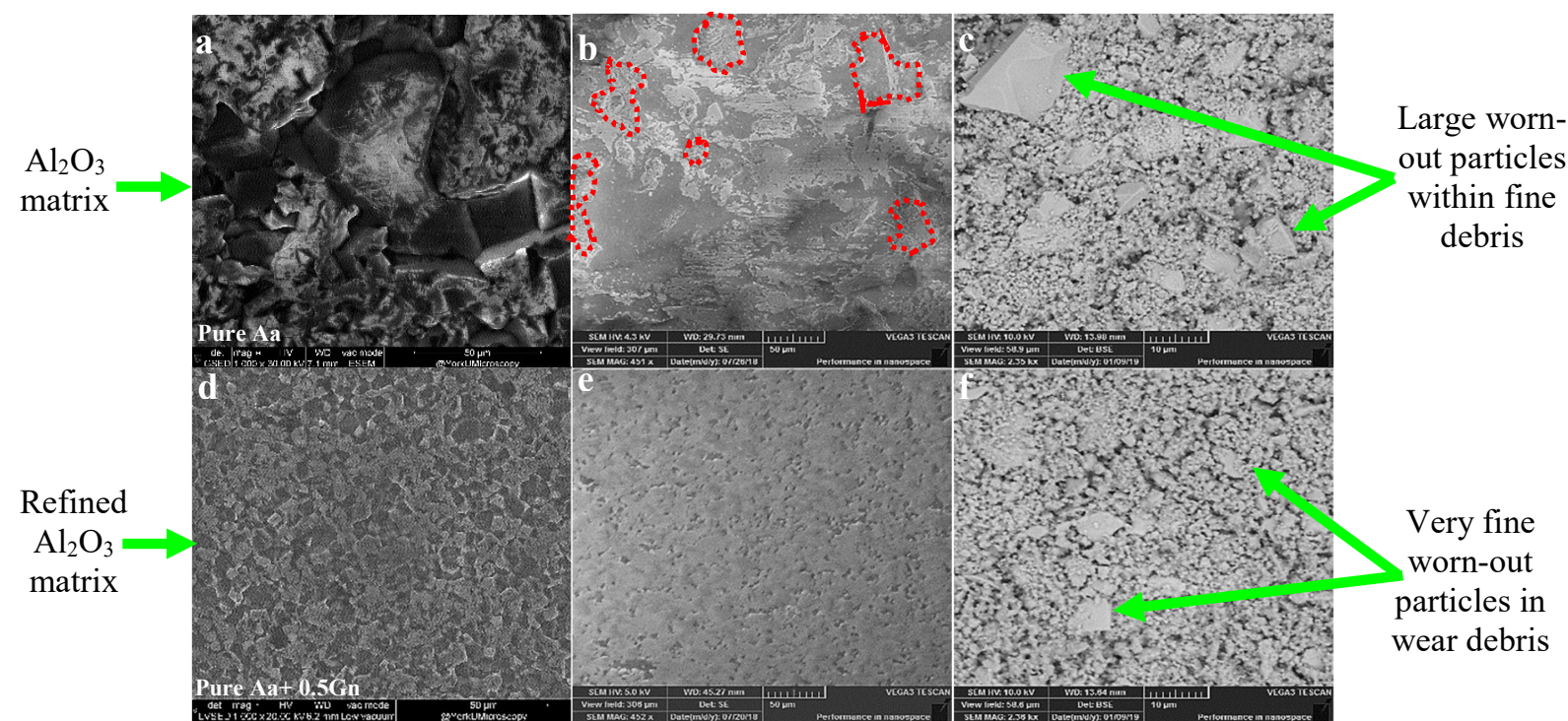

Figure 2. SEM micrographs of $\mathrm{Al}_{2} \mathrm{O}_{3}$ matrix nanocomposites (a) as-sintered coarse structure of Pure $\mathrm{Al}_{2} \mathrm{O}_{3}$ before wear (b) wear track of Pure $\mathrm{Al}_{2} \mathrm{O}_{3}$ showing large peel-off areas (c) wear debris of Pure $\mathrm{Al}_{2} \mathrm{O}_{3}$ showing large pulled-out particle (d) as-sintered refined $\mathrm{Al}_{2} \mathrm{O}_{3}+0.5 \mathrm{Gn}$ microstructure (d) within wear track of $\mathrm{Al}_{2} \mathrm{O}_{3}+0.5 \mathrm{Gn}$ (f) wear debris of $\mathrm{Al}_{2} \mathrm{O}_{3}+0.5 \mathrm{Gn}$ showing small and fine worn-out particles. 